\title{
Estimation of Cutoff Values of Cotinine in Urine and Saliva for Pregnant Women in Poland
}

\author{
Joanna Stragierowicz, ${ }^{1}$ Karolina Mikołajewska, ${ }^{1}$ Marta Zawadzka-Stolarz, ${ }^{2}$ \\ Kinga Polańska, ${ }^{3}$ and Danuta Ligocka ${ }^{1}$ \\ ${ }^{1}$ Department of Toxicology and Carcinogenesis, Nofer Institute of Occupational Medicine, 8 Teresy Street, 91-348 Lodz, Poland \\ ${ }^{2}$ Nofer Institute of Occupational Medicine, 8 Teresy Street, 91-348 Lodz, Poland \\ ${ }^{3}$ Department of Environmental Epidemiology, Nofer Institute of Occupational Medicine, 8 Teresy Street, 91-348 Lodz, Poland
}

Correspondence should be addressed to Danuta Ligocka; ligocka@imp.lodz.pl

Received 26 April 2013; Accepted 16 September 2013

Academic Editor: Peter P. Egeghy

Copyright (C) 2013 Joanna Stragierowicz et al. This is an open access article distributed under the Creative Commons Attribution License, which permits unrestricted use, distribution, and reproduction in any medium, provided the original work is properly cited.

Setting appropriate cutoff values and the use of a highly sensitive analytical method allow for correct classification of the smoking status. Urine-saliva pairs samples of pregnant women in the second and third trimester, and saliva only in the first trimester were collected. Offline SPE and LC-ESI-MS/MS method was developed in the broad concentration range (saliva $0.4-1000 \mathrm{ng} / \mathrm{mL}$, urine $0.8-4000 \mathrm{ng} / \mathrm{mL}$ ). The mean recoveries were $3.7 \pm 7.6 \%$ for urine and $99.1 \pm 2.6 \%$ for saliva. LOD for saliva was $0.12 \mathrm{ng} / \mathrm{mL}$ and for urine $0.05 \mathrm{ng} / \mathrm{mL}$; LOQ was $0.4 \mathrm{ng} / \mathrm{mL}$ and $0.8 \mathrm{ng} / \mathrm{mL}$, respectively. Intraday and interday precision equaled, respectively, $1.2 \%$ and $3.4 \%$ for urine, and $2.3 \%$ and $6.4 \%$ for saliva. There was a strong correlation between salivary cotinine and the uncorrected cotinine concentration in urine in the second and third trimesters of pregnancy. The cutoff values were established for saliva $12.9 \mathrm{ng} / \mathrm{mL}$ and urine $42.3 \mathrm{ng} / \mathrm{mL}$ or $53.1 \mu \mathrm{g} / \mathrm{g}$ creatinine with the ROC curve analysis. The developed analytical method was successfully applied to quantify cotinine, and a significant correlation between the urinary and salivary cotinine levels was found. The presented cut-off values for salivary and urinary cotinine ensure a categorization of the smoking status among pregnant women that is more accurate than self-reporting.

\section{Introduction}

The most commonly used biomarker of exposure to tobacco smoke is cotinine, as a metabolite of nicotine. The measurement of the cotinine concentration in various biological fluids is directly proportional to the degree of exposure to nicotine [1]. The determination of cotinine is recommended for the assessment of active tobacco smoking, monitoring of environmental tobacco smoke (ETS) exposure, and impact evaluation of smoking cessation programs [2]. The most important advantage of using cotinine as a biomarker of tobacco smoke and ETS is the fact that about $72 \%$ of nicotine is converted to cotinine [3] and the half-life of cotinine averages about 17 hours, in comparison to the one averaging $2-3 \mathrm{~h}$ in case of nicotine [4]. The total nicotine content in tobacco (by weight of tobacco) averaged $10.2 \mathrm{mg}$ [5], while the nicotine intake per cigarette averaged $1.04 \mathrm{mg}$ [6], representing about $10 \%$.

According to the Global Adult Tobacco Survey (GATS) in Poland, in 2009, approximately $24 \%$ of women aged $15-49$ years were smokers (out of whom $21 \%$ were daily cigarette smokers) [7]. Based on the Pregnancy-related Assessment Monitoring Survey (PrAMS), the most recent results show that even more than $12 \%$ of pregnant women in Poland smoke [8].

The effect of tobacco smoking is not limited to the one of nicotine, which is responsible for addiction to smoking, but also involves the influence of various toxic substances released from burning cigarettes, like carbon monoxide, PAHs, heterocyclic compounds, N-nitrosoamines, aromatic 
amines, N-heterocyclic amines, aldehydes, or volatile hydrocarbons, among which 69 are known carcinogens [9-11]. The most important adverse health effects associated with maternal cigarette smoking are premature rupture of membranes, placental abruption or preeclampsia [12], uteroplacental insufficiency, and reducing the blood flow to the fetus. Maternal smoking may also result in lower birth weight of the newborns [11]. Based on the analysis performed in Poland, in the newborns prenatally exposed to ETS, the birth weight was lower by $335 \mathrm{~g} \pm 90.3$ than that in the case of the nonexposed newborns $(P<0.001)$ after adjustment for maternal educational level, marital status, prepregnancy weight, child gender, and gestational age [13]. Maternal nicotine exposure may cause changes in the development and maturing of the offspring's lungs, which can result in the organ being more susceptible to disease and likely to manifest reduced lung function [14]. Smoking during pregnancy may have longterm consequences on the neurobehavioral development of children [8].

Due to numerous highly adverse effects of smoking during pregnancy, there is a need to monitor the extent of exposure, spread the knowledge of these effects to the fetus, and promote smoking cessation. Evaluation of the smoking status among pregnant women is based mainly on a self-reported questionnaire. However, only a confirmation by a laboratory analysis may lead to correct and reliable classification since pregnant women (and not only they) are reluctant to admit that they smoke.

Interindividual variability in the metabolism of nicotine is due to the gender and ethnic differences in the activity of enzymes (CYP2A6 and UGT1A) and, to some extent, genetic polymorphisms of the CYP2A6 gene [15]. Like many other physiological processes, also the metabolism of nicotine changes during pregnancy. The observed variability in the metabolic clearance of cotinine may markedly increase by $140 \%$ during pregnancy, resulting in a half-life shorter by nearly $50 \%$ than the one in the nonpregnant state [16].

The explanation of these changes could be the influence of a higher concentration of estradiol during pregnancy [17], which induces the activity of CYP2A6 responsible for the metabolism of nicotine [18].

As reported by Rebagliato et al. [19], the salivary cotinine level was significantly lower during pregnancy, compared with the postpartum one. Therefore, it is necessary to identify a cutoff value to avoid misclassification of smoking and nonsmoking pregnant women.

The ROC analysis is increasingly used to determine the cut-off values for biomarkers of exposure to tobacco smoke [20-23].

The primary aim of this study was to establish the optimal cut-off value for cotinine in saliva and urine of pregnant women in Poland and to compare the diagnostic effectiveness of three smoking tests: cotinine in saliva and in urine and in urine with creatinine correction. The secondary one was to develop a sensitive and specific method for determining the cotinine level in urine and saliva in a broad range of concentrations. Finally, our aim was also to estimate the utility of these matrices for both rapid screening used in order to identify potential smokers and more accurate determination of the degree of exposure to tobacco smoke, especially that concerning pregnant women.

\section{Methods}

2.1. Population. From the biobank of the Polish Mother and Child Cohort Study (REPRO PL), saliva-urine samples collected in trimester II and III of 69 women were selected as well as the survey data on the smoking status of the pregnant woman, the smoking habit of her husband/partner, and a consent to smoking in the apartment. In addition, each of these women had a saliva sample taken during the first trimester of pregnancy. The complete description of the cohort was published elsewhere [24]. In short, the inclusion criteria were single pregnancy up to 12 weeks of gestation, no assisted conception, no pregnancy complications, and no chronic diseases as specified in the study protocol [24]. The mean age of 69 women was $26.41 \pm 4.97$ years. Based on the survey data, it was found that in the first trimester 19/69 women were smokers and, in the second and third trimesters, this ratio equaled $17 / 69$. Smoking was permitted in $52 \%$ of the apartments in the first trimester of pregnancy, but in the third trimester such permission to smoke at home decreased by approximately $9 \%$.

To find the correlations between the matrices, we analyzed saliva and urine samples collected at the same time.

2.2. Standards and Reagents. Cotinine (98\%), internal standard-cotinine- $\mathrm{d}_{3}$ (98\%), and ammonium acetate (98\%) were obtained from Sigma Aldrich. Acetonitrile and Methanol Ultra Gradient HPLC Grade were supplied by Baker. Acetic acid (>99\%) was purchased from Fluka. Ultrapure water was obtained from Milli-Q-Plus, Ultra-PureWater System (Millipore USA). All working standards of cotinine and cotinine$\mathrm{d}_{3}$ were prepared in acetonitrile and stored at $-20^{\circ} \mathrm{C}$. Solid phase extraction manifold was maintained on Supelco, and OASIS HLB LP 96-Well Plate $60 \mu \mathrm{m}$ ( $60 \mathrm{mg}$ ) was supplied by Waters (USA). Control urine lyophilized ClinCheck/Control, for toxic organic compounds, was purchased from Recipe Chemicals (Germany).

2.3. Biological Samples Collection. Saliva was collected from pregnant women into a Salivette with citric acid (Sarstedt, Germany). The amount of approximately 1-2 $\mathrm{mL}$ of saliva was easily obtained by having the women chew a cotton swab, at least $30 \mathrm{~min}$ after eating or drinking. A clear, fluid sample was obtained by centrifuging the Salivette and used for analysis. A $50 \mathrm{~mL}$ volume of morning urine was collected from pregnant women to a $100 \mathrm{~mL}$ polypropylene container (Bene, Poland). All saliva and urine samples were transported to the laboratory in a cool box and stored at $-20^{\circ} \mathrm{C}$ until analysis.

2.4. Samples Preparation. Urine and saliva samples were thawed before the analysis, thoroughly mixed, and transferred into $2.0 \mathrm{~mL}$ polypropylene tubes. The samples were centrifuged for $10 \mathrm{~min}$ at $11000 \mathrm{rcf}$ (MIKRO 120, Hettich Zentrifugen, Tuttlingen, Germany). To $0.25 \mathrm{~mL}$ of urine or $0.5 \mathrm{~mL}$ of saliva, water and $20 \mu \mathrm{L}$ of internal standard (cotinine- $\mathrm{d}_{3}$ ) were added and mixed vigorously. Each well of the Oasis 
TABLE 1: Validation parameters of the LC-MS/MS method of determination of cotinine in saliva and urine.

\begin{tabular}{lccccccc}
\hline & $\begin{array}{c}\text { LOD } \\
{[\mathrm{ng} / \mathrm{mL}]}\end{array}$ & $\begin{array}{c}\text { LOQ } \\
{[\mathrm{ng} / \mathrm{mL}]}\end{array}$ & $\begin{array}{c}\text { Range of linearity } \\
{[\mathrm{ng} / \mathrm{mL}]}\end{array}$ & $\begin{array}{c}\text { Correlation coefficient } \\
r^{2}\end{array}$ & $\begin{array}{c}\text { Uncertainty } \\
(k=2)[\%]\end{array}$ & $\begin{array}{c}\text { Accuracy } \\
{[\%]}\end{array}$ & $\begin{array}{c}\text { Recovery } \\
\text { [\%] }\end{array}$ \\
\hline Urine & 0.05 & 0.8 & $0.8-4000$ & 0.9997 & 9.3 & 4.27 & $93.72 \pm 7.6$ \\
Saliva & 0.05 & 0.4 & $0.4-1000$ & 0.9993 & 6.0 & 2.33 & $99.10 \pm 2.6$ \\
\hline
\end{tabular}

${ }^{*}$ All values are means $\pm \mathrm{SD}$.

HLB extraction plate was prewashed with $2 \mathrm{~mL}$ of acetonitrile followed by $2 \mathrm{~mL}$ of water. Then, the samples were placed on the plate and washed with $1.0 \mathrm{~mL}$ of water (in case of saliva samples) and $1.0 \mathrm{~mL}$ of $20 \%$ methanol in water (in case of urine samples). The analytes were eluted with $1 \mathrm{~mL}$ of acetonitrile, and $20 \mu \mathrm{L}$ of the extract was injected into the chromatographic system.

2.5. Calibration. The working solutions were prepared by appropriate dilutions of the standard stock solutions. The standard stock solutions of $1 \mathrm{mg}$ cotinine or cotinine- $\mathrm{d}_{3} / \mathrm{mL}$ were further diluted with acetonitrile to obtain the working solutions of cotinine $(10 \mu \mathrm{g} / \mathrm{mL}, 400 \mathrm{ng} / \mathrm{mL}$, and $20 \mathrm{ng} / \mathrm{mL})$ and cotinine- $\mathrm{d}_{3}(2.5 \mu \mathrm{g} / \mathrm{mL})$. Calibration standards were prepared for saliva at the following concentrations: $0.2 ; 0.5$; $1.0 ; 5.0 ; 10 ; 50 ; 100 ; 200 ; 500 \mathrm{ng} / \mathrm{mL}$ and for urine $0.2 ; 0.5 ; 1.0$; $5.0 ; 10 ; 50 ; 100 ; 200 ; 500 ; 1000 \mathrm{ng} / \mathrm{mL}$. All working solutions were stored at $-20^{\circ} \mathrm{C}$. Calibration curves were generated using linear regression with $1 / \mathrm{X}$ weighting.

2.6. Liquid Chromatography-Mass Spectrometry. The chromatographic separation was performed using the Waters 2695 Alliance LC System (Waters, USA) on the analytical column X-Terra MS C $183.5 \mu \mathrm{m} 2.1 \times 150$ mm (Waters).

The following mobile phase was used: A 7\% (water containing $0.04 \%$ of ammonium acetate with $0.05 \%$ of acetic acid) and B 93\% (acetonitrile) with an isocratic mode and flow rate of $0.2 \mathrm{~mL} / \mathrm{min}$.

The Micromass Quattro Micro API tandem mass spectrometer (Waters, USA) was coupled to the HPLC Alliance system. The mass spectrometer was operated in the electrospray positive mode; the capillary was kept at $1.0 \mathrm{kV}$ and the source temperature was maintained at $130^{\circ} \mathrm{C}$, the desolvation gas flow was $600 \mathrm{~L} / \mathrm{h}$ and the desolvation temperature was kept at $350^{\circ} \mathrm{C}$, and the cone energy was $33 \mathrm{~V}$ and the collision energy was $21 \mathrm{eV}$ for both cotinine and cotinine- $\mathrm{d}_{3}$. The specific ion transitions for cotinine and cotinine- $\mathrm{d}_{3}$ were monitored in a multiple reaction monitoring mode (MRM) with a dwell time of $0.3 \mathrm{~s}$.

2.7. Creatinine Correction. The creatinine level was determined according to the Jaffe automated method. Urine samples with a creatinine concentration lower than $0.3 \mathrm{~g} / \mathrm{L}$ or higher than $3.0 \mathrm{~g} / \mathrm{L}$ were excluded [25].

2.8. Statistical Analysis. Receiver operating characteristic (ROC) curve analysis was used for three purposes: to test the performance of the diagnostic system (how close to 1 is AUC), to compare the performance of the three tests, and to establish the optimal cut-off values for cotinine in saliva and in urine and creatinine-corrected concentration in urine. Statistical analysis was performed based on the measurement of cotinine in the biological material, taking into account the self-reported information on smoking and the data from the questionnaires concerning the ETS exposure at home of samples donors. The level of statistical significance was kept at $P<0.05$. The ROC analysis module of the IBM program SPSS ver. 20.0 (IBM SPSS) was used for the ROC curves analysis and comparison of the area under the curve (AUC).

The correlation between the cotinine concentrations in saliva and urine was analyzed with the IBM SPSS Statistics 20.0 .

\section{Results}

3.1. Optimization of the HPLC-MS/MS Conditions. The mass spectrometer conditions were optimized by monitoring cotinine and cotinine- $\mathrm{d}_{3}$ ion pairs for quantification in the MRM mode. The best results were achieved with $\mathrm{m} / \mathrm{z}$ transitions of quantification traces, $177.2>80.2 ; 180.2>80.2$, and confirmation, $177.2>98.2 ; 180.2>101.2$, for cotinine and cotinine- $\mathrm{d}_{3}$, respectively.

The retention time of cotinine and cotinine- $\mathrm{d}_{3}$ was approx-imately $2.5 \mathrm{~min}$, and the total run time equaled $6 \mathrm{~min}$. The use of the structurally identical internal standard (cotinine- $\mathrm{d}_{3}$ ) eliminated most of the quantification errors.

3.2. Linearity. The relationship between the response and concentration of cotinine in a range of $0.4-1000 \mathrm{ng} / \mathrm{mL}$ (for saliva samples) and $0.8-4000 \mathrm{ng} / \mathrm{mL}$ (for urine samples) was linear, with the correlation coefficient $(r)$ of the calibration curve $r>0.998$ or higher. Detailed parameters of the method validation are presented in Table 1.

3.3. Sensitivity. The limit of detection (LOD) defined as the concentration of an analyte that gives at least a $3: 1$, signal tonoise ratio was $0.12 \mathrm{ng} / \mathrm{mL}$ (for saliva) and $0.05 \mathrm{ng} / \mathrm{mL}$ (for urine), and the limit of quantification (LOQ), defined as the concentration of an analyte that gives at least a $10: 1$ signalto-noise ratio, was $0.4 \mathrm{ng} / \mathrm{mL}$ (for saliva) and $0.8 \mathrm{ng} / \mathrm{mL}$ (for urine).

3.4. Precision and Recovery. The intraday and interday precisions of the method were estimated by the analysis of control urine (ClinCheck, Level 1) and saliva samples (saliva from smokers) at the concentration of $248 \mathrm{ng} / \mathrm{mL}$ of urine (control range $198-298 \mathrm{ng} / \mathrm{mL}$ ) and about $250 \mathrm{ng} / \mathrm{mL}$ of saliva on the same day and on four consecutive days (Table 2 ).

To determine the recovery of the extraction from the urine and saliva samples, seven different cotinine levels were 
TABLE 2: Recovery of cotinine in urine and saliva samples.

\begin{tabular}{lccc}
\hline & $\begin{array}{c}\text { Expected value } \\
{[\mathrm{ng} / \mathrm{mL}]}\end{array}$ & $\begin{array}{c}\text { Measured }^{*} \\
{[\mathrm{ng} / \mathrm{mL}]}\end{array}$ & Recovery [\%] \\
\hline & 0.8 & $0.63 \pm 0.01$ & 78.5 \\
Urine & 40 & $38.8 \pm 3.4$ & 97 \\
Before spiking & 80 & $76.4 \pm 3$ & 95.6 \\
$0.884 \pm 0.055 \mathrm{ng} / \mathrm{mL}$ & 120 & $113.1 \pm 4.6$ & 94.3 \\
& 2000 & $1977 \pm 96.3$ & 98.8 \\
& 3800 & $3728 \pm 76.6$ & 98.1 \\
\hline & 0.4 & $0.40 \pm 0.037$ & 100.5 \\
Saliva & 20 & $20.06 \pm 0.56$ & 100.3 \\
Before spiking & 40 & $38.4 \pm 4.2$ & 95.9 \\
$0.701 \pm 0.041 \mathrm{ng} / \mathrm{mL}$ & 80 & $80 \pm 2.9$ & 100.5 \\
& 120 & $113.6 \pm 2.2$ & 94.7 \\
& 500 & $506.1 \pm 7.36$ & 101.1 \\
& 900 & $907 \pm 10.5$ & 100.7 \\
\hline
\end{tabular}

${ }^{*}$ All values are means $\pm \mathrm{SD}$.

TABLE 3: Intraday and interday precision of cotinine in urine and saliva samples.

\begin{tabular}{lcccccc}
\hline Sample & \multicolumn{3}{c}{$\begin{array}{c}\text { Intraday precision } \\
\text { Mean }\end{array}$} & \multicolumn{3}{c}{ Interday precision } \\
& $n$ & RSD [\%] & $n$ & $\begin{array}{c}\text { Mean } \\
{[\mathrm{ng} / \mathrm{mL} / \mathrm{mL}]}\end{array}$ & RSD [\%] \\
\hline Urine & 3 & 257.5 & 1.2 & 12 & 259.0 & 3.4 \\
Saliva & 4 & 243.3 & 2.3 & 16 & 244.9 & 6.4 \\
\hline
\end{tabular}

added. Three repetitions of each concentration level were analyzed, and the ratio of the measured amounts to the added amounts was calculated (Table 3 ).

3.5. Tests of Usability: Smoking and Nonsmoking Women. To test the usability of the method, in total 138 pairs of urinesaliva samples were analyzed (69 pairs in trimester II and 69 pairs in trimester III), as well as 69 saliva samples collected in trimester I. In all urine and saliva samples, the concentrations of cotinine were above LOD (Table 4).

To assess the correlations between the matrices, the linear regression and Pearson's correlations were calculated. The results are shown in Figure 1. The correlations between the saliva and the uncorrected cotinine concentration in urine in trimester II $(r=0.932)$ and III $(r=0.925)$ were higher than the aggregated data of trimester II and III $(r=0.851)$, both being statistically significant $(P<0.01)$. Similar trends were observed for the correlation between saliva and creatininecorrected cotinine in urine, but the corresponding $r$ values were lower, that is, $0.720,0.865$, and 0.780 , for trimester II, III, and the total period of pregnancy, respectively.

To verify the smoking status, various questionnaires are usually taken into account. In this study, we took into account information on the smoking status obtained in the survey.

The research model was used to compare different matrices (saliva, urine) and the creatinine correction of cotinine concentrations of urine. Also, an analysis was conducted of the effect of the period in the pregnancy on the cut-off value.
Statistical analysis was performed to compare the cotinine concentrations in the samples taken from women at different periods of pregnancy. Saliva samples were collected during periodic medical examinations in trimester I, II, and III of pregnancy and urine samples in trimester II and III.

Receiver operating characteristic (ROC) curve analysis is a graphical and quantitative technique used for determination of the optimal cut-off value. Selecting the optimal cut-off value for individual biomarkers of smoking was conducted using the Youden's index, J, which is defined as the maximum sum of sensitivity and specificity decreased by 1 , that is: $J_{\max }=$ (sensitivity + specificity) - 1 [26]. The cut-off value is "optimal" when the index has the maximum value.

On the basis of the content of cotinine in saliva, the cut-off values for the corresponding uncorrected cotinine in urine and creatinine-corrected urine were calculated. The optimized cut-off values and parameters of ROC curves analysis of cotinine in saliva and urine for pregnant women are shown in Table 5.

When choosing the optimal cut-off value, it is important to take into account both sensitivity and specificity, and the maximum value of Youden's index was the decisive factor.

ROC analysis showed that the optimal cut-off value separating smokers and nonsmokers for saliva varies depending on the period of pregnancy and equals $31.9 \mathrm{ng} / \mathrm{mL}$ for the first trimester, $18.1 \mathrm{ng} / \mathrm{mL}$ for the second one, and $11.47 \mathrm{ng} / \mathrm{mL}$ for the last one with the sensitivity of $100 \%$ and specificity of $96 \%$ for all tests. In addition, the optimum cut-off value was determined on the level of $18.8 \mathrm{ng} / \mathrm{mL}(98.3 \%, 89.6, n=241)$ for cotinine in saliva throughout pregnancy (trimesters I, II, and III).

The optimal cut-off value for cotinine in the urine samples collected in trimester II was higher than in trimester III both for the urine- $53 \mathrm{ng} / \mathrm{mL}$ versus $34.44 \mathrm{ng} / \mathrm{mL}$ and the creatinine corrected concentration- $68.35 \mu \mathrm{g} / \mathrm{g}$ creatinine versus $48.53 \mu \mathrm{g} / \mathrm{g}$ creatinine (Table 5).

The ROC analysis for the combined samples taken during the period from the second to the third trimester of pregnancy showed lower cut-off values for the cotinine level in all tested matrices, $12.45 \mathrm{ng} / \mathrm{mL}$ for saliva and $42.3 \mathrm{ng} / \mathrm{mL}$ and $53.09 \mu \mathrm{g} / \mathrm{g}$ creatinine for urine with the sensitivity equaling $100 \%$ and specificity of $95 \%$. (Table 5 ).

The determined cut-off for cotinine in saliva samples collected at the beginning of the pregnancy was $31.9 \mathrm{ng} / \mathrm{mL}$ (sensitivity $100 \% /$ specificity $96 \%$ ).

These values were established to distinguish between pregnant smokers and nonsmokers.

\section{Discussion}

We developed and validated the method for rapid, sensitive, and specific determination of cotinine in urine and saliva. By achieving the low limit of quantification $(0.4 \mathrm{ng} / \mathrm{mL}$ for saliva and $0.8 \mathrm{ng} / \mathrm{mL}$ for urine), the presented method can be useful to assess the exposure to tobacco smoke as ETS and active smoking. Using the noninvasive methods of sampling biological material, like urine or saliva, the smoking status can be more easily assessed, especially with lower volume of biological fluids, than in other studies. 

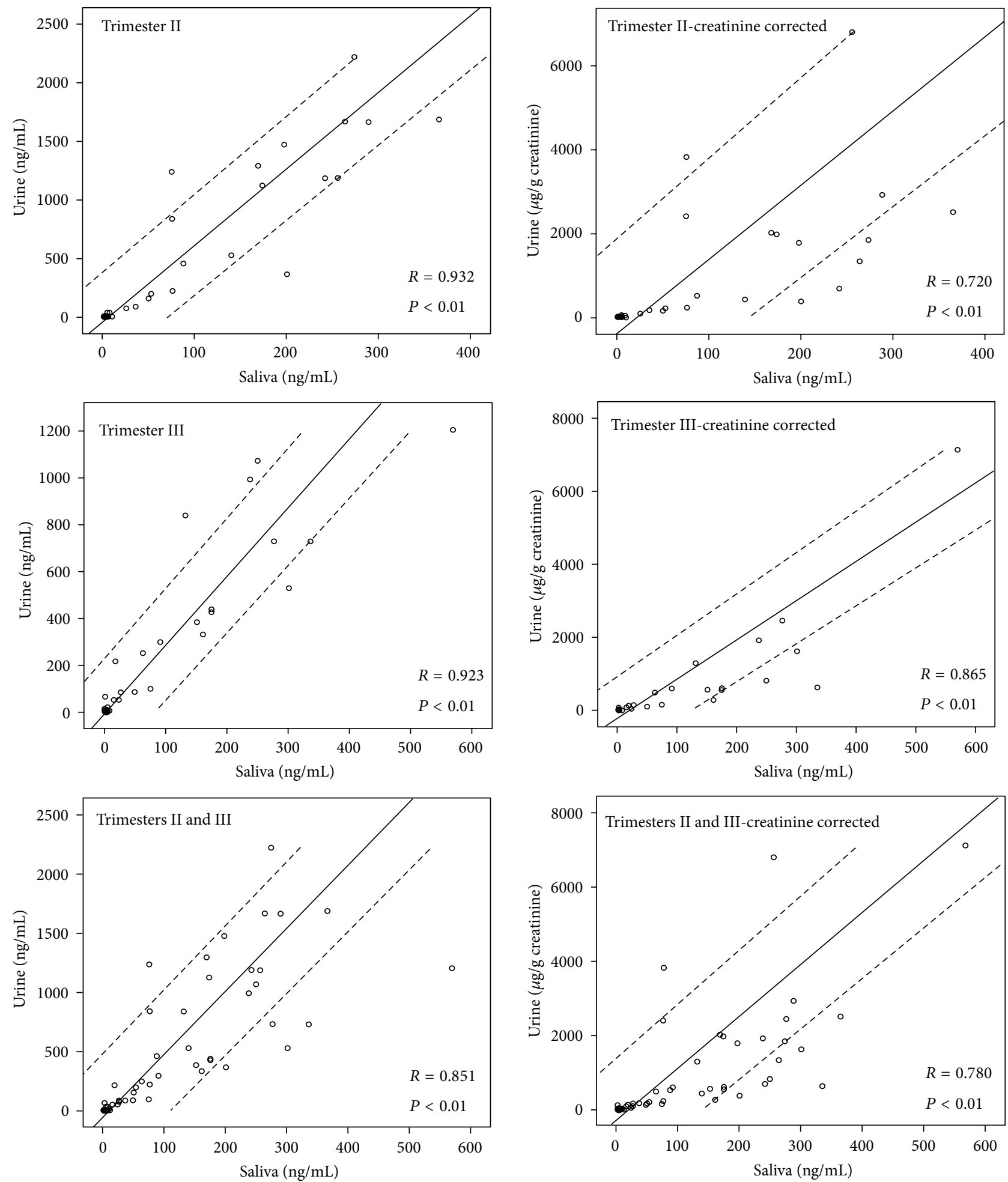

FIGURE 1: Comparison of the urinary and salivary cotinine concentrations, depending on the trimester of pregnancy and creatinine corrected concentration. 
TABLE 4: Cotinine in saliva and urine classification based on self-reporting smoking status.

\begin{tabular}{|c|c|c|c|c|c|c|}
\hline & & $N$ & $\mathrm{AM}$ & $\mathrm{SD}$ & GM & $95 \% \mathrm{CI}$ \\
\hline \multicolumn{7}{|l|}{ Nonsmoking } \\
\hline \multirow{3}{*}{ Saliva } & Trimester I & 50 & 5.99 & 6.88 & 4.437 & $4.376-4.498$ \\
\hline & Trimester II & 52 & 4.86 & 8.42 & 3.190 & $3.116-3.263$ \\
\hline & Trimester III & 52 & 3.86 & 4.14 & 3.060 & $3.024-3.096$ \\
\hline \multirow{2}{*}{ Urine } & Trimester II & 52 & 10.78 & 29.31 & 4.497 & $4.242-4.751$ \\
\hline & Trimester III & 52 & 10.27 & 32.50 & 3.070 & $2.787-3.352$ \\
\hline \multirow{2}{*}{ Urine corrected } & Trimester II & 52 & 14.33 & 35.61 & 5.531 & $5.221-5.841$ \\
\hline & Trimester III & 52 & 14.43 & 30.14 & 5.546 & $5.267-5.826$ \\
\hline \multicolumn{7}{|l|}{ Smoking } \\
\hline \multirow{3}{*}{ Saliva } & Trimester I & 19 & 175.77 & 91.69 & 151.88 & 150.561-153.199 \\
\hline & Trimester II & 17 & 174.42 & 98.67 & 141.92 & $140.424-143.425$ \\
\hline & Trimester III & 17 & 181.40 & 139.97 & 128.45 & 126.319-130.577 \\
\hline \multirow{2}{*}{ Urine } & Trimester II & 17 & 1021.97 & 632.79 & 747.67 & $738.044-757.292$ \\
\hline & Trimester III & 17 & 500.15 & 368.45 & 341.72 & $336.115-347.323$ \\
\hline \multirow{2}{*}{ Urine corrected } & Trimester II & 17 & 1758.4 & 1703.8 & 1017.31 & $991.395-1043.22$ \\
\hline & Trimester III & 17 & 1133.2 & 1685.8 & 545.10 & $519.465-570.741$ \\
\hline
\end{tabular}

TABLE 5: Optimized cutoff values of cotinine in saliva and urine for pregnant women (Youden's index 0.956 \pm 0.0084 ).

\begin{tabular}{|c|c|c|c|c|c|c|c|c|}
\hline & \multicolumn{2}{|c|}{ Smoking } & \multirow{2}{*}{$\mathrm{AUC}^{*}$} & \multirow{2}{*}{ SE } & \multirow{2}{*}{$95 \% \mathrm{CI}$} & \multirow{2}{*}{ Cutoff } & \multirow{2}{*}{ Sensitivity } & \multirow{2}{*}{ Specificity } \\
\hline & Yes & No & & & & & & \\
\hline Saliva & & & & & & {$[\mathrm{ng} / \mathrm{mL}]$} & & \\
\hline Trimester I & 19 & 50 & 0.998 & 0.003 & $0.992-1.000$ & 31.90 & $100 \%$ & $96 \%$ \\
\hline Trimester II & 17 & 52 & 0.997 & 0.004 & $0.989-1.000$ & 18.10 & $100 \%$ & $96 \%$ \\
\hline Trimester III & 17 & 52 & 0.997 & 0.004 & $0.989-1.000$ & 11.47 & $100 \%$ & $96 \%$ \\
\hline Trimesters II \& III & 34 & 104 & 0.997 & 0.003 & $0.992-1.000$ & 12.85 & $100 \%$ & $96 \%$ \\
\hline Urine & & & & & & {$[\mathrm{ng} / \mathrm{mL}]$} & & \\
\hline Trimester II & 17 & 52 & 0.997 & 0.004 & $0.989-1.000$ & 53.00 & $100 \%$ & $96 \%$ \\
\hline Trimester III & 17 & 52 & 0.991 & 0.008 & $0.976-1.000$ & 34.44 & $100 \%$ & $94 \%$ \\
\hline Trimesters II \& III & 34 & 104 & 0.994 & 0.004 & $0.997-1.000$ & 42.31 & $100 \%$ & $95 \%$ \\
\hline Urine corrected & & & & & & {$[\mu \mathrm{g} / \mathrm{g}]$} & & \\
\hline Trimester II & 17 & 52 & 0.995 & 0.005 & $0.986-1.000$ & 68.35 & $100 \%$ & $96 \%$ \\
\hline Trimester III & 17 & 52 & 0.990 & 0.008 & $0.974-1.000$ & 48.53 & $100 \%$ & $94 \%$ \\
\hline Trimesters II \& III & 34 & 104 & 0.993 & 0.004 & $0.984-1.000$ & 53.09 & $100 \%$ & $95 \%$ \\
\hline
\end{tabular}

${ }^{*} P<0.0001$.

A number of other analytical methods have been applied for the measurement of cotinine in urine or saliva including immunological methods, for example, enzyme linked immunosorbent assay (ELISA, LOD $=1.3 \mathrm{ng} / \mathrm{mL}$ ). However, cross-reactivity is still the major concern for immunological methods, especially with nicotine metabolites: $3^{\prime}$-hydroxycotinine and $3^{\prime}$-hydroxycotinine-glucuronide [27]. The most commonly used analytical techniques are gas chromatography with flame-ionization detection (GC-FID, LOQ = $500 \mathrm{ng} / \mathrm{mL}$ ) [28], mass spectrometry (GC-MS, LOQ = $10 \mathrm{ng} / \mathrm{mL}$ ) [29], and liquid chromatography with mass spectrometry (UPLC-MS/MS, LOQ = $1.1 \mathrm{ng} / \mathrm{mL}$ ) [30, 31]. These methods have been used to distinguish smokers from nonsmokers. Many gas chromatographic methods are characterized by relatively high limits of quantification, which makes it more complicated to access the ETS exposure. In this case, the method of choice should make it possible to achieve a limit of detection lower than $1 \mathrm{ng} / \mathrm{mL}$ [32]. In order to evaluate such low concentrations, it is very important to minimize ion suppression, in particular in the chromatography method coupled with mass spectrometry or tandem mass spectrometry. Many analytical methods do not use internal standards or use structurally different internal standards than radiolabeled compounds, such as milrinone [33], diphenylamine [34], and acetaminophen [35], which may contribute to the increase of ion suppression [36].

A current state-of-the-art method for determination of cotinine in biological material is liquid chromatography with mass spectrometry (LC-MS/MS) and atmospheric pressure or electrospray ionization which gives high sensitivity. The results of our study offered a method characterized by improved sensitivity, selectivity, and high throughput in 

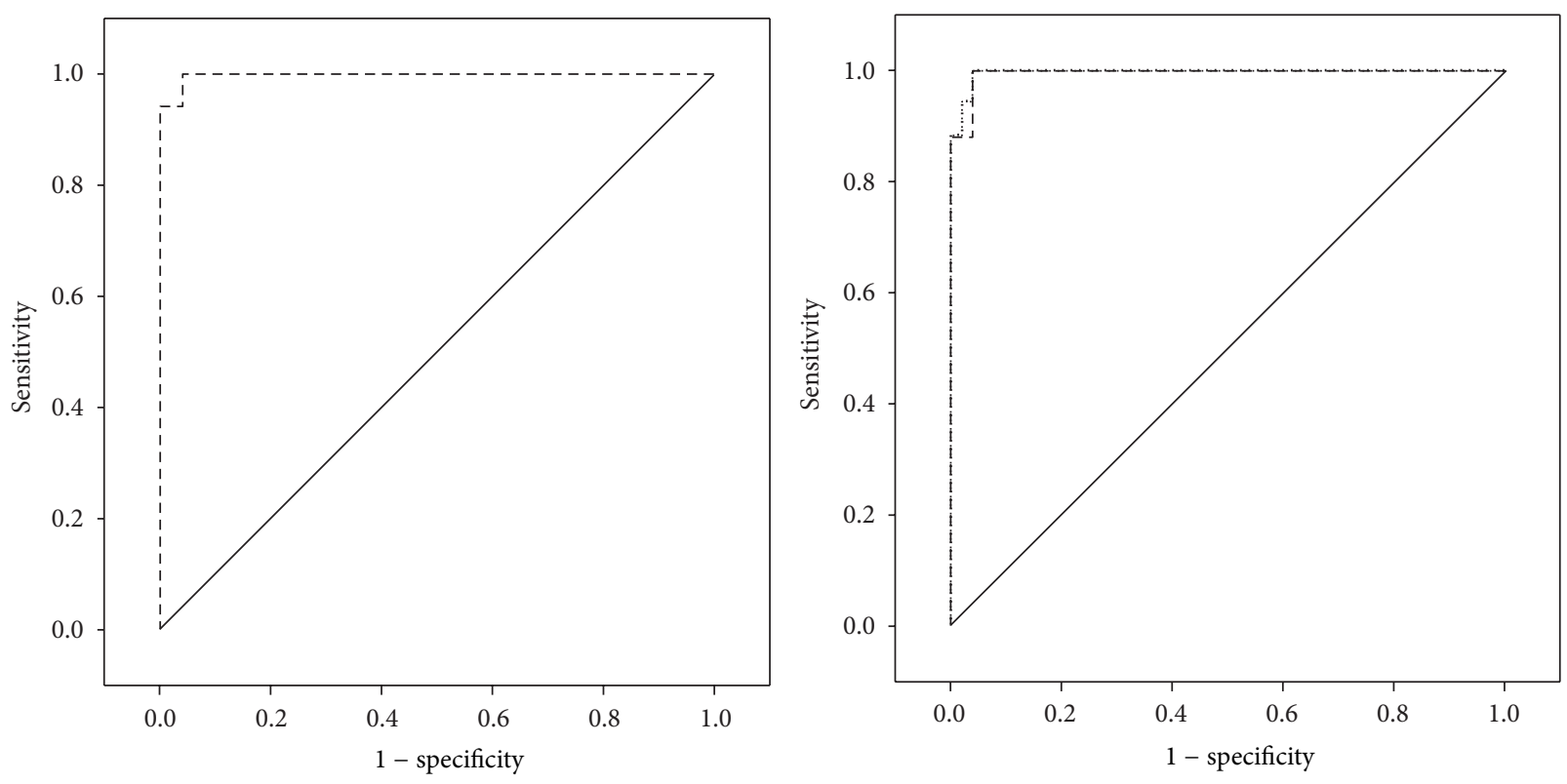

- - - Saliva-trimester I

Trimester II

..... Saliva

...... Urine
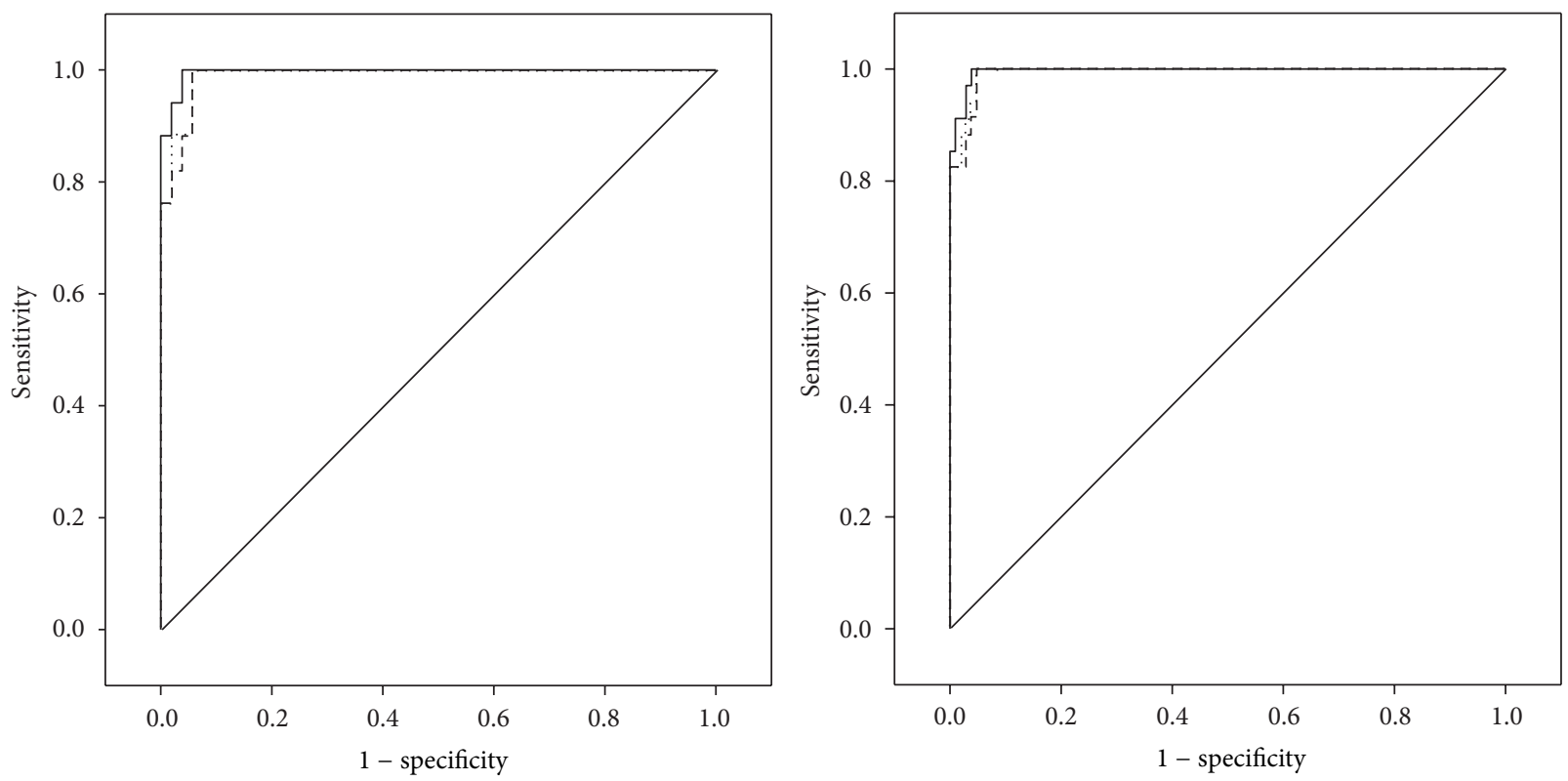

Trimester III

- Saliva

- - - Urine corrected

Trimesters II and III

- Saliva

- - - Urine corrected

FIGURE 2: ROC curves analysis of smoking status based on questionnaires and measurement of cotinine in saliva and in urine and creatinine corrected cotinine in urine are shown in Figure 2.

comparison to other conventional techniques. The structurally identical deuterated internal standard (cotinine- $\mathrm{d}_{3}$ ) increases the selectivity of the method, eliminates the effect of ion suppression, and results in higher precision and accuracy of the measurement. The advantage of the use of the 96-well extraction plate is the possibility to cleanup multiple samples, blank, and quality control samples, in parallel under the same conditions. This sample preparation procedure makes it possible to achieve a lower limit of detection (LOD = $0.05 \mathrm{ng} / \mathrm{mL}$ ) by minimizing the matrix effect with only 0.25 $\mathrm{mL}$ of urine or $0.5 \mathrm{~mL}$ of saliva needed for the analysis.

So far, many studies have been published concerning cotinine cutoff points, yet only a few included pregnant women. In 1998, Klebanoff et al. [37] established a serum 
cotinine cut-off value $10 \mathrm{ng} / \mathrm{mL}$ for pregnant women which corresponds to the concentration in saliva of $12.5 \mathrm{ng} / \mathrm{mL}$. This estimation is based on the study of Jarvis who discovered that the concentration of cotinine in saliva is 1.25 times higher than in serum [38]. For the nonpregnant women-14 ng/mL serum [39] and $12 \mathrm{ng} / \mathrm{mL}$ [40]. In Japan, for a large validation study $(n=5128)$ on tobacco smoke exposure during pregnancy, the cutoff for serum cotinine was established at $11.48 \mathrm{ng} / \mathrm{mL}$ which corresponds to $14.35 \mathrm{ng} / \mathrm{mL}$ in saliva [41]. As for saliva, the values obtained for pregnant women were on the level of $13 \mathrm{ng} / \mathrm{mL}[42]$ and $24 \mathrm{ng} / \mathrm{mL}[43,44]$.

Interindividual variabilities in the metabolism of nicotine are due to the gender- and ethnicity-dependent differences in the activity of enzymes (CYP2A6 and UGT1A) or, to some extent, genetic polymorphisms of the CYP2A6 gene [15].

As for urine, the results recorded among pregnant women were $100 \mathrm{ng} / \mathrm{mL}$ [45] and among the nonpregnant ones$50 \mathrm{ng} / \mathrm{mL}$ [39], $200 \mathrm{ng} / \mathrm{mL}$ [46], and $550 \mathrm{ng} / \mathrm{mL}$ [21].

From the physiological point of view, pregnancy is a dynamic process, during which there increases, inter alia, the volume of blood (30-40\%) [47], distribution volume and rate of nicotine metabolism [16].

Probably, these are the main reasons for which the cutoff values for cotinine in saliva and urine at different stages of pregnancy may differ materially from those set for the general population. In our study, we compared changes in the concentration of cotinine in the samples taken from women at different times of pregnancy during periodic medical examinations. The cut-off values determined for trimester II, and III for both saliva and urine indicate a slight change (reduction). However, the difference between the values determined for the first trimester for saliva, that is, $31.9 \mathrm{ng} / \mathrm{mL}$, was significantly higher for those determined for the second trimester and third trimester, respectively, $18.1 \mathrm{ng} / \mathrm{mL}$ and $11.47 \mathrm{ng} / \mathrm{mL}$. In view of the relatively small changes in the metabolism of nicotine in early pregnancy, the cut-off value of $31.9 \mathrm{ng} / \mathrm{mL}$ for that period may be taken as a defining value for nonpregnant women.

The correct determination of the smoking status is particularly important in epidemiological studies assessing the effects of exposure to environmental factors on the outcome of pregnancy, where smoking is an important confounding factor that should be taken into account in the analysis and interpretation of results.

Minimizing the number of misclassified cases, we estimated the optimal cutoff point for pregnant women as $12.85 \mathrm{ng} / \mathrm{mL}$ for salivary cotinine and $42.3 \mathrm{ng} / \mathrm{mL}$ or $53.1 \mu \mathrm{g} / \mathrm{g}$ creatinine for urinary cotinine. The observed slight decrease of cotinine cut-off values both for saliva and urine in trimester III as compared with II confirms the previous findings. These findings correspond to those obtained in a Nakayima and Yokoi's study where a large interindividual variability in cotinine N-glucuronidation (ca. 89-fold) in human microsomes in vitro was reported [14]. The hypothesis concerning a decrease of the free cotinine concentration in the body fluids of pregnant women may clarify our observation but still needs verification in the further research.

In our study, cotinine concentrations in urine samples were compared with those in saliva samples to estimate the differences and correlations between the matrices. For the urinary and salivary cotinine levels in the second and third trimesters, high correlations were observed, better for salivaurine than for saliva-creatinine-corrected urine. That confirms the findings of a previous study on the lesser use of creatinine correction $[48,49]$. The mean urinary creatinine concentration in our study was $0.89 \mathrm{~g} / \mathrm{L}$ (with the results $<0.3 \mathrm{~g} / \mathrm{L}$, the mean was $0.82 \mathrm{~g} / \mathrm{L}$ ), which is a much lower result compared with the nonpregnant women aged 20-49, with the mean being $1.2 \mathrm{~g} / \mathrm{L}$ [50]. A more reliable parameter for the assessment of diuresis would be obtained if the collection of 24-hour urine samples was used. However, in epidemiologic studies, spot samples are more practical than $24 \mathrm{hr}$ urine samples [50].

For the monitoring of exposure to tobacco smoke, usually only one type of biological samples is collected. The choice of the sample type depends on the purpose of the study and the analytical technique that is available in the laboratory. This is particularly important in case of nonsmokers, where the expected concentrations are very low. Our study shows that the levels of cotinine in urine are about 4-5.5 times higher than in saliva, depending on the use of creatinine correction. On the other hand, saliva is a matrix that is easier to clean up than urine. All the advantages and disadvantages of those matrices must be taken into account while selecting the method of sample preparation and analytical technique. In this study, we used saliva samples for rapid screening of the smoking status. Urinary cotinine can be used to estimate more precisely the level of exposure to tobacco smoke, especially in nonsmokers, and to differentiate the nonexposed nonsmokers and exposed nonsmokers. In our analysis, we took into account only the survey data as a criterion for classification as smokers-nonsmokers, but a widespread lack of acceptance for smoking during pregnancy may be a cause of untrue answers.

In 2007, Zielińska-Danch et al. set a cut-off value for cotinine in urine of $500 \mathrm{ng} / \mathrm{mL}$ for the general population [21]. In later studies, Zielińska-Danch et al. [22] using ROC curve analysis obtained the value of 327 micrograms/g creatinine.

Exposure to the second-hand smoke is region specific, and in some countries a low level of exposure results in a much lower cutoff cotinine value. Until 2009, many studies referred to the cut-off value established by Jarvis et al. [39] that equaled $14 \mathrm{ng} / \mathrm{mL}$ serum for the general population, while the new value of $4.47 \mathrm{ng} / \mathrm{mL}$ (corresponding to $5.59 \mathrm{ng} / \mathrm{mL}$ saliva) for women was established as a result of the NHANES survey [20]. However, the authors proposed a general cut-off point of $3 \mathrm{ng} / \mathrm{mL}$ or ethnic-specific values between 1 and $6 \mathrm{ng} / \mathrm{mL}$ serum [20]. Benowitz et al. [20] established also a urine cut-off value of $15 \mathrm{ng} / \mathrm{mL}$ using an extrapolation of the above results and average ratios of cotinine in urine and plasma.

The cut-off value for cotinine in urine (determined by Goniewicz et al. [23]) equaling $31.5 \mathrm{ng} / \mathrm{mL}(n=637)$ represents the multiethnic population, including the Poles, that is likely to be exposed to tobacco smoke in the same way as the group of pregnant women studied in our research.

The optimal saliva cut-off value of $12.9 \mathrm{ng} / \mathrm{mL}$ is comparable to that equaling $14.35 \mathrm{ng} / \mathrm{mL}$ saliva (derived form 
$11.48 \mathrm{ng} / \mathrm{mL}$ plasma) obtained for Japanese pregnant women [41]. Most likely, the high cutoff point concerning Polish pregnant women represents a similar second-hand exposure to tobacco smoke. Taking into account the smoke-free law, the substantial reduction of the ETS exposure can be expected, as well as a decrease of tobacco smoke biomarkers (cotinine in saliva and urine). As a consequence, also lower a cut-off value might be established.

\section{Conclusion}

The results of the analytical method validation indicate that the developed procedure can be applied for routine determination of cotinine in urine and saliva samples. Achieving a low limit of quantification $(0.4 \mathrm{ng} / \mathrm{mL}$ for saliva and $0.8 \mathrm{ng} / \mathrm{mL}$ for urine) allows not only distinguishing between smokers and nonsmokers but also quantifing the exposure to environmental tobacco smoke and degree of active smoking. Our results showed a significant correlation between the urinary and salivary cotinine levels. Our study presents for the first time results of ROC curve analysis used to determine the cut-off values for the assay of cotinine in saliva and urine and in creatinine-corrected urine as a marker of exposure to tobacco smoke in women during different periods of pregnancy in order to distinguish their status of smoking. This is the first such study of pregnant women in Poland.

The ROC analysis with the application of the Youden's index helped to determine the optimal cut-off value for cotinine in saliva $(18.9 \mathrm{ng} / \mathrm{mL})$ and in urine $(42.3 \mathrm{ng} / \mathrm{mL}$ and $53.1 \mu \mathrm{g} / \mathrm{g}$ creatinine) for the first time for pregnant women in Poland.

The analysis of the diagnostic usefulness of cotinine determination in saliva and urine and the evaluation of the usefulness of the creatinine correction of the cotinine level showed that all three proposed cut-off values are characterized by high sensitivity and specificity.

Our results suggest that, during the interpretation of the analysis of cotinine, the period of pregnancy when the samples of urine or saliva are taken for the assessment of exposure to tobacco smoke may have some significance.

\section{Conflict of Interests}

The authors declare that they have no conflict of interests.

\section{Acknowledgment}

The research was supported by the Grant PNRF-218-AI-1/07 from Norway through the Norwegian Financial Mechanism within the Polish-Norwegian Research Fund.

\section{References}

[1] N. L. Benowitz, "Biomarkers of environmental tobacco smoke exposure," Environmental Health Perspectives, vol. 107, no. 2, pp. 349-355, 1999.

[2] SRNT Subcommittee on Biochemical Verification, "Biochemical verification of tobacco use and cessation," Nicotine and Tobacco Research, vol. 4, no. 2, pp. 149-159, 2002.
[3] N. L. Benowitz and P. Jacob III, "Metabolism of nicotine to cotinine studied by a dual stable isotope method," Clinical Pharmacology and Therapeutics, vol. 56, no. 5, pp. 483-493, 1994.

[4] N. L. Benowitz, "Cotinine as a biomarker of environmental tobacco smoke exposure," Epidemiologic Reviews, vol. 18, no. 2, pp. 188-204, 1996.

[5] L. T. Kozlowski, N. Y. Mehta, C. T. Sweeney et al., "Filter ventilation and nicotine content of tobacco in cigarettes from Canada, the United Kingdom, and the United States," Tobacco Control, vol. 7, no. 4, pp. 369-375, 1998.

[6] N. L. Benowitz and P. Jacob III, "Daily intake of nicotine during cigarette smoking," Clinical Pharmacology and Therapeutics, vol. 35, no. 4, pp. 499-504, 1984.

[7] Global Adult Tobacco Survey (GATS), "Fact Sheet Poland: 2009-2010," http://nccd.cdc.gov/GTSSData/Ancillary/DataReports.aspx?CAID $=1$.

[8] A. Wojtyła, M. Goździewska, P. Paprzycki, and P. Biliński, "Tobacco-related foetal origin of adult diseases hypothesispopulation studies in Poland," Annals of Agricultural and Environmental Medicine, vol. 19, no. 1, pp. 117-128, 2012.

[9] V. Haufroid and D. Lison, "Urinary cotinine as a tobaccosmoke exposure index. A minireview," International Archives of Occupational and Environmental Health, vol. 71, no. 3, pp. 162168, 1998.

[10] IARC, IARC Monographs on Evaluation of Carcinogenic Risks to Humans, Volume 83: Tobacco Smoke and Involuntary Smoking, WHO International Agency for Research on Cancer, Lyon, France, 2002.

[11] N. L. Benowitz and D. A. Dempsey, "Pharmacotherapy for smoking cessation during pregnancy," Nicotine and Tobacco Research, vol. 6, supplement 2, pp. S189-S202, 2004.

[12] A. Castles, E. K. Adams, C. L. Melvin, C. Kelsch, and M. L. Boulton, "Effects of smoking during pregnancy: five meta-analyses," The American Journal of Preventive Medicine, vol. 16, no. 3, pp. 208-215, 1999.

[13] K. Polańska, W. Hanke, W. Sobala, and D. Ligocka, "Impact of prenatal environmental tobacco smoke exposure on birth parameters," Przegl, Lekarski, vol. 67, no. 10, pp. 835-837, 2010.

[14] G. S. Maritz and R. Harding, "Life-long programming implications of exposure to tobacco smoking and nicotine before and soon after birth: evidence for altered lung development," International Journal of Environmental Research and Public Health, vol. 8, no. 3, pp. 875-898, 2011.

[15] M. Nakajima and T. Yokoi, "Interindividual variability in nicotine metabolism: C-oxidation and glucuronidation," Drug Metabolism and Pharmacokinetics, vol. 20, no. 4, pp. 227-235, 2005.

[16] D. Dempsey, P. Jacob III, and N. L. Benowitz, "Accelerated metabolism of nicotine and cotinine in pregnant smokers," Journal of Pharmacology and Experimental Therapeutics, vol. 301, no. 2, pp. 594-598, 2002.

[17] E. Higashi, T. Fukami, M. Itoh et al., "Human CYP2A6 is induced by estrogen via estrogen receptor," Drug Metabolism and Disposition, vol. 35, no. 10, pp. 1935-1941, 2007.

[18] E. S. Messina, R. F. Tyndale, and E. M. Sellers, "A major role for CYP2A6 in nicotine C-oxidation by human liver microsomes," Journal of Pharmacology and Experimental Therapeutics, vol. 282, no. 3, pp. 1608-1614, 1997.

[19] M. Rebagliato, F. Bolumar, C. D. V. Florey et al., "Variations in cotinine levels in smokers during and after pregnancy," The American Journal of Obstetrics and Gynecology, vol. 178, no. 3, pp. 568-571, 1998. 
[20] N. L. Benowitz, J. T. Bernert, R. S. Caraballo, D. B. Holiday, and J. Wang, "Optimal serum cotinine levels for distinguishing cigarette smokers and nonsmokers within different racial/ ethnic groups in the United States between 1999 and 2004," The American Journal of Epidemiology, vol. 169, no. 2, pp. 236-248, 2009.

[21] W. Zielińska-Danch, W. Wardas, A. Sobczak, and I. SzołtysekBołdys, "Estimation of urinary cotinine cut-off points distinguishing non-smokers, passive and active smokers," Biomarkers, vol. 12, no. 5, pp. 484-496, 2007.

[22] W. Zielińska-Danch, M. L. Goniewicz, I. Szołtysek-Bołdys et al., "Estimation of optimal levels of tobacco biomarkers to distinguish active and passive smokers using ROC analysis," Przegḷ Lekarski, vol. 66, no. 10, pp. 636-640, 2009.

[23] M. L. Goniewicz, M. D. Eisner, E. Lazcano-ponce et al., "Comparison of urine cotinine and the tobacco-specific nitrosamine metabolite 4-(methylnitrosamino)-1-(3-pyridyl)-1-butanol (NNAL) and their ratio to discriminate active from passive smoking," Nicotine and Tobacco Research, vol. 13, no. 3, pp. 202208, 2011.

[24] K. Polańska, W. Hanke, J. Gromadzińska et al., "Polish mother and child cohort study-defining the problem, the aim of the study and methodological assumptions," International Journal of Occupational Medicine and Environmental Health, vol. 22, no. 4, pp. 383-391, 2009.

[25] WHO, Biological Monitoring of Chemicals Exposure in the Workplace, vol. 1, WHO, Geneva, Switzerland, 1996.

[26] N. J. Perkins and E. F. Schisterman, "The inconsistency of optimal" cutpoints obtained using two criteria based on the receiver operating characteristic curve," The American Journal of Epidemiology, vol. 163, no. 7, pp. 670-675, 2006.

[27] A. Matsumoto, T. Ino, M. Ohta et al., "Enzyme-linked immunosorbent assay of nicotine metabolites," Environmental Health and Preventive Medicine, vol. 15, no. 4, pp. 211-216, 2010.

[28] F. Kardani, A. Daneshfar, and R. Sahrai, "Determination of nicotine, anabasine, and cotinine in urine and saliva samples using single-drop microextraction," Journal of Chromatography $B$, vol. 878, no. 28, pp. 2857-2862, 2010.

[29] J. S. Toraño and H. J. M. van Kan, "Simultaneous determination of the tobacco smoke uptake parameters nicotine, cotinine and thiocyanate in urine, saliva and hair, using gas chromatographymass spectrometry for characterisation of smoking status of recently exposed subjects," Analyst, vol. 128, no. 7, pp. 838-843, 2003.

[30] J. Kuhn, T. Vollmer, C. Martin, D. Hendig, and C. Knabbe, "Fast and sample cleanup-free measurement of nicotine and cotinine by stable isotope dilution ultra-performance liquid chromatography-tandem mass spectrometry," Journal of Pharmaceutical and Biomedical Analysis, vol. 67-68, pp. 137-143, 2012.

[31] P. Jacob III, L. Yu, M. Duan, L. Ramos, O. Yturralde, and N. L. Benowitz, "Determination of the nicotine metabolites cotinine and trans- $3^{\prime}$-hydroxycotinine in biologic fluids of smokers and non-smokers using liquid chromatography-tandem mass spectrometry: biomarkers for tobacco smoke exposure and for phenotyping cytochrome P450 2A6 activity," Journal of Chromatography B, vol. 879, no. 3-4, pp. 267-276, 2011.

[32] L. Song, W. Davis, S. M. Abrams et al., "Sensitive and rapid method for the determination of urinary cotinine in nonsmokers: an application for studies assessing exposures to second hand smoke (SHS)," Analytica Chimica Acta, vol. 545, no. 2, pp. 200-208, 2005.
[33] R. Q. Gabr, M. E. Elsherbiny, V. Somayaji, P. T. Pollak, and D. R. Brocks, "A liquid chromatography-mass spectrometry method for nicotine and cotinine; utility in screening tobacco exposure in patients taking amiodarone," Biomedical Chromatography, vol. 25, no. 10, pp. 1124-1131, 2011.

[34] H. S. Shin, J. G. Kim, Y. J. Shin, and S. H. Jee, "Sensitive and simple method for the determination of nicotine and cotinine in human urine, plasma and saliva by gas chromatography-mass spectrometry," Journal of Chromatography B, vol. 769, no. 1, pp. 177-183, 2002.

[35] R. Apinan, A. Choemung, and K. Na-Bangchang, "A sensitive HPLC-ESI-MS-MS method for the determination of cotininein urine," Journal of Chromatographic Science, vol. 48, no. 6, pp. 460-465, 2010.

[36] L. L. Jessome and D. A. Volmer, "Ion suppression: a major concern in mass spectrometry," LC-GC North America, vol. 24, no. 5, pp. 498-510, 2006.

[37] M. A. Klebanoff, R. J. Levine, J. D. Clemens, R. Dersimonian, and D. G. Wilkins, "Serum cotinine concentration and selfreported smoking during pregnancy," The American Journal of Epidemiology, vol. 148, no. 3, pp. 259-262, 1998.

[38] M. J. Jarvis, P. Primatesta, B. Erens, C. Feyerabend, and A. Bryant, "Measuring nicotine intake in population surveys: comparability of saliva cotinine and plasma cotinine estimates," Nicotine and Tobacco Research, vol. 5, no. 3, pp. 349-355, 2003.

[39] M. J. Jarvis, H. Tunstall-Pedoe, C. Feyerabend, C. Vesey, and Y. Saloojee, "Comparison of tests used to distinguish smokers from nonsmokers," The American Journal of Public Health, vol. 77, no. 11, pp. 1435-1438, 1987.

[40] M. J. Jarvis, J. Fidler, J. Mindell, C. Feyerabend, and R. West, "Assessing smoking status in children, adolescents and adults: cotinine cut-points revisited," Addiction, vol. 103, no. 9, pp. 1553-1561, 2008.

[41] S. Sasaki, T. S. Braimoh, T. A. Yila, E. Yoshioka, and R. Kishi, "Self-reported tobacco smoke exposure and plasma cotinine levels during pregnancy - a validation study in Northern Japan," Science of the Total Environment, vol. 412-413, pp. 114-118, 2011.

[42] H. K. Hegaard, H. Kjaergaard, L. F. Møller, H. Wachmann, and B. Ottesen, "Determination of a saliva cotinine cut-off to distinguish pregnant smokers from pregnant non-smokers," Acta Obstetricia et Gynecologica Scandinavica, vol. 86, no. 4, pp. 401406, 2007.

[43] L. Owen and A. McNeill, "Saliva cotinine as indicator of cigarette smoking in pregnant women," Addiction, vol. 96, no. 7, pp. 1001-1006, 2001.

[44] N. R. Boyd, R. A. Windsor, L. L. Perkins, and J. B. Lowe, "Quality of measurement of smoking status by self-report and saliva cotinine among pregnant women," Maternal and Child Health Journal, vol. 2, no. 2, pp. 77-83, 1998.

[45] H. J. Jhun, H. G. Seo, D. H. Lee et al., "Self-reported smoking and urinary cotinine levels among pregnant women in Korea and factors associated with smoking during pregnancy," Journal of Korean Medical Science, vol. 25, no. 5, pp. 752-757, 2010.

[46] S. L. Bramer and B. A. Kallungal, "Clinical considerations in study designs that use cotinine as a biomarker," Biomarkers, vol. 8, no. 4, pp. 187-203, 2003.

[47] W. J. McGanity, E. B. Dawson, and A. Fogelman, "Nutrition in pregnancy and lactation," in Modern Nutrition in Health and Disease, M. E. Shils, J. A. Olson, and M. Shike, Eds., pp. 705726, Lea and Febiger, London, UK, 8th edition, 1994. 
[48] P. Jatlow, S. McKee, and S. S. O'Malley, "Correction of urine cotinine concentrations for creatinine excretion: is it useful?" Clinical Chemistry, vol. 49, no. 11, pp. 1932-1934, 2003.

[49] G. O. Petersen, C. E. Leite, J. M. Chatkin, and F. V. Thiesen, "Cotinine as a biomarker of tobacco exposure: development of a HPLC method and comparison of matrices," Journal of Separation Science, vol. 33, no. 4-5, pp. 516-521, 2010.

[50] D. B. Barr, L. C. Wilder, S. P. Caudill, A. J. Gonzalez, L. L. Needham, and J. L. Pirkle, "Urinary creatinine concentrations in the U.S. population: implications for urinary biologic monitoring measurements," Environmental Health Perspectives, vol. 113, no. 2, pp. 192-200, 2005. 


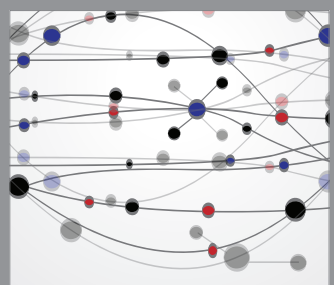

The Scientific World Journal
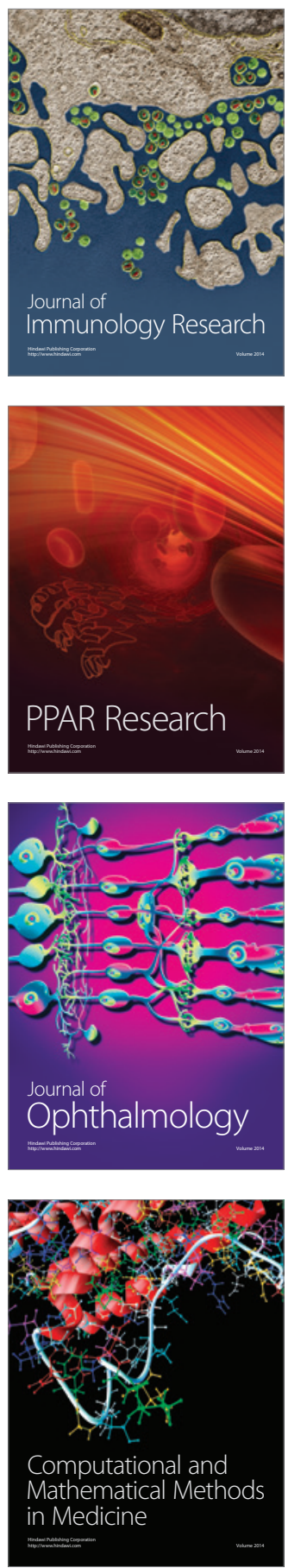

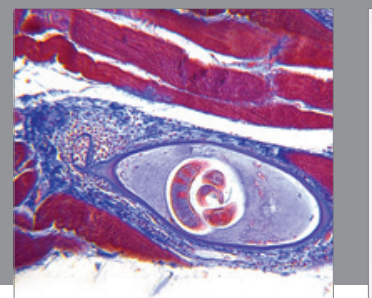

Gastroenterology

Research and Practice
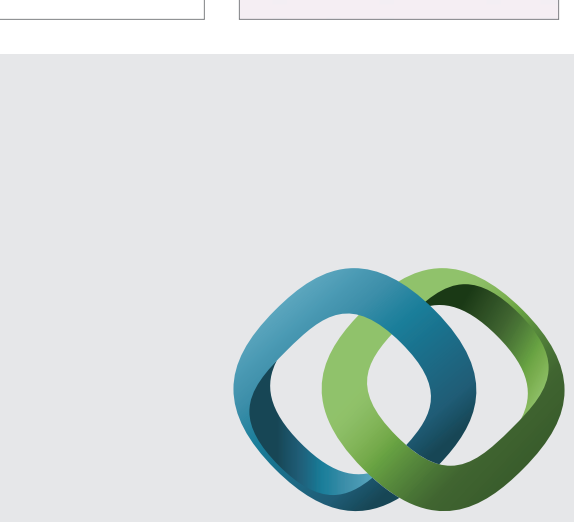

\section{Hindawi}

Submit your manuscripts at

http://www.hindawi.com
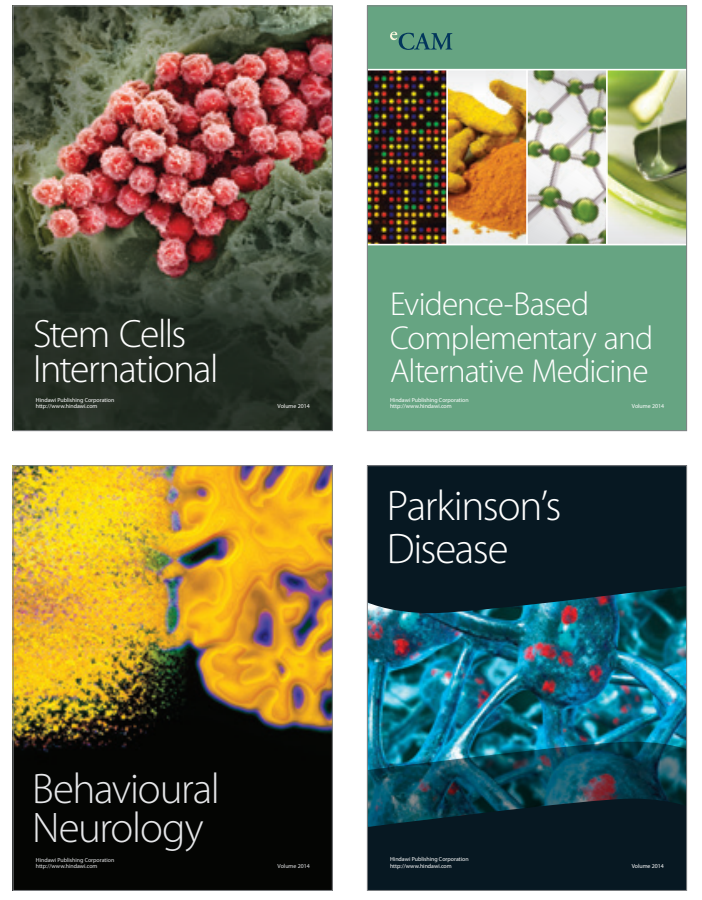
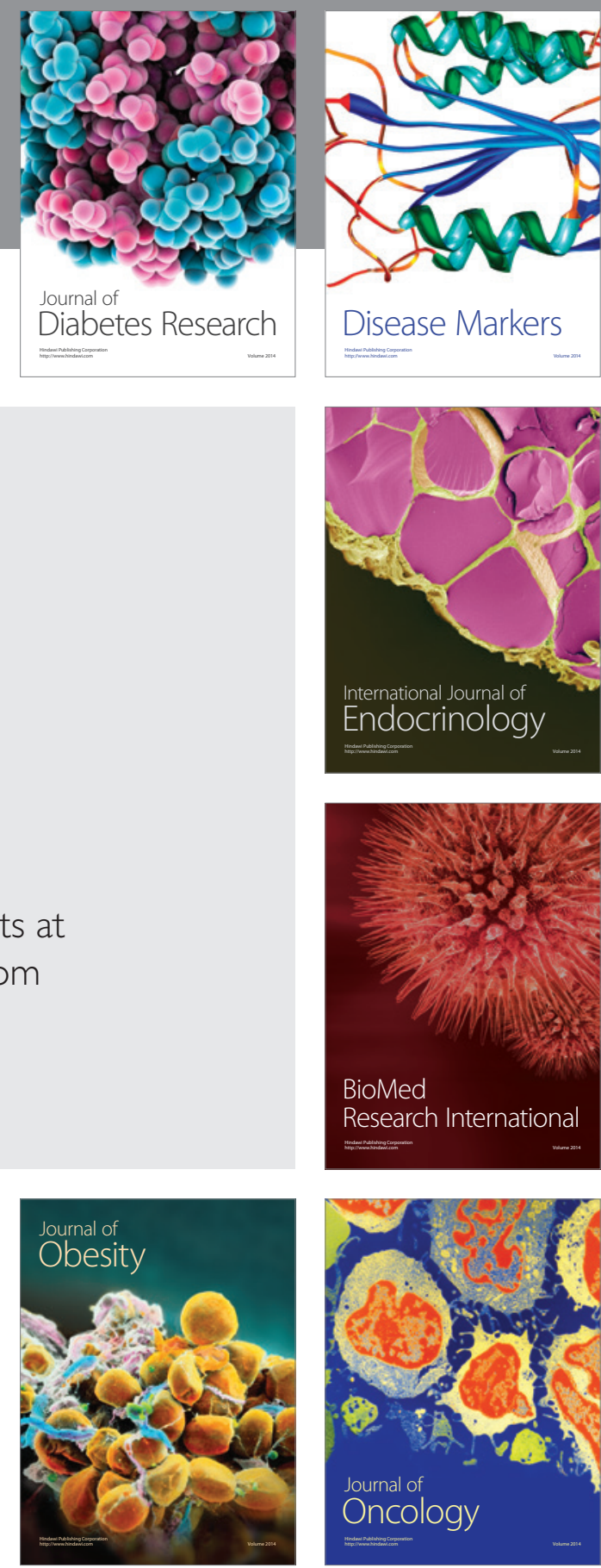

Disease Markers
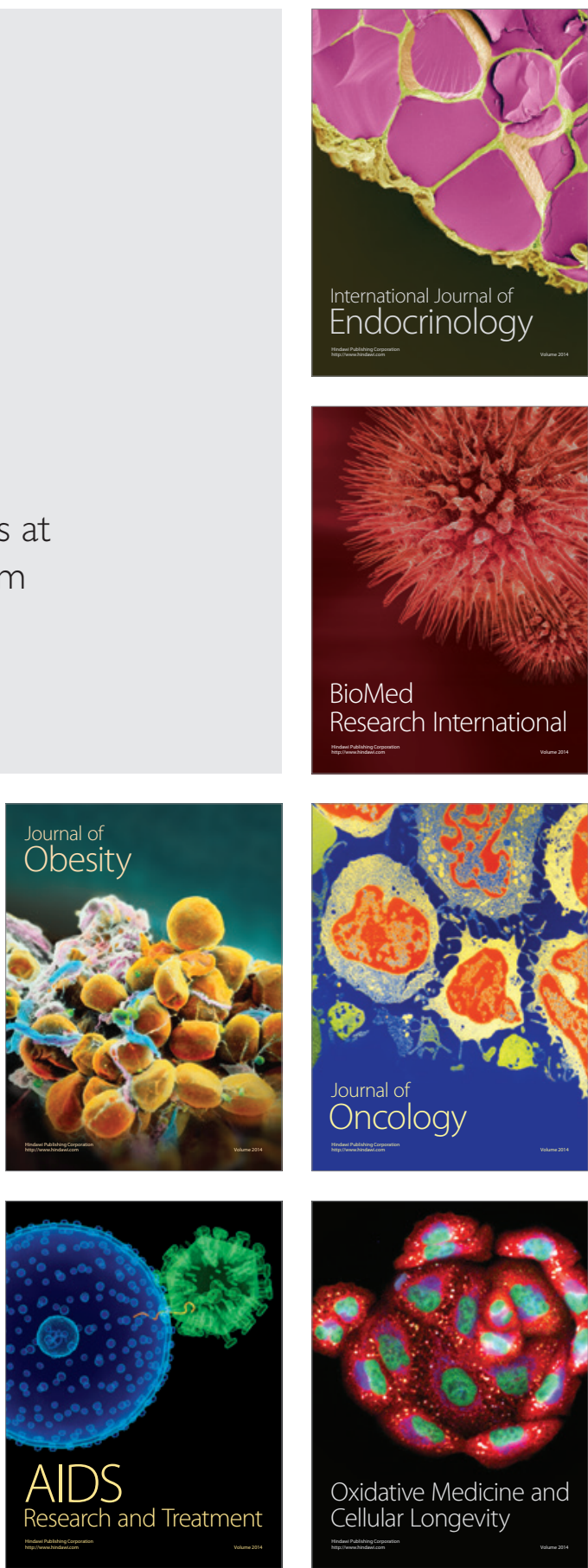